\title{
The Effect of Two Scoring Methods on Multiple Choice Agricultural Science Test Scores
}

\author{
B. K. Ajayi \\ Faculty of Education, Ekiti State University \\ P.O.Box 2205, Ado-Ekiti, Ekiti-State, Nigeria \\ Tel: 234-803-731-4475Ｅmail: Bolanlekike@yahoo.com
}

M. S. Omirin

Faculty of Education, Ekiti State University

P.O.Box 2205, Ado-Ekiti, Ekiti-State, Nigeria

Tel: 234-803-396-3827

Received: December 1, 2011

Accepted: February 3, 2012 Published: March 1, 2012

doi:10.5539/res.v4n1p255

URL: http://dx.doi.org/10.5539/res.v4n1p255

\begin{abstract}
The study investigated the effect of two scoring methods on multiple choice agricultural sciences test scores, to find the most favourable method to be used, the interaction effect of two methods of scoring in the schools, types of school and the states. The research design used was combination of survey type and one short experimental design. A sample of 1,200 students was selected by stratified random sampling techniques in south western Nigeria. Two hypotheses were generated and tested at 0.05 level of significance using $t$ - test and correlation analysis. The result of the analysis showed that, there was significant relationship between the performance of students whose scripts were marked with number right scoring method and those marked with logical choice weight scoring method. The study revealed that logical choice weight scoring method was a better method that favoured the scoring of the students in multiple choice Agricultural Science test. Based on this findings, it was recommended that logical choice weight should be introduced to teachers for use in the classroom as a new method of scoring multiple choice tests in both Junior and Senior Secondary Schools.
\end{abstract}

Keywords: Multiple choice, Logical choice weight, Number right scoring method, Interactive effect, Reliability, Testee, Distractor

\section{Introduction}

Assessment of students' achievement is very paramount and central to the current Nigerian system of education at all levels. There is an evidence to support the concept that students learn the way they are taught and examined, for instance if a teacher's test is always for factual knowledge the students will soon learn to expect only knowledge oriented questions, whereas, if he or she test in higher cognitive abilities, the students will learn to prepare for such questions. That is, the way the teacher and test affect the pattern of learning by students and consequently their academic performance. Tests are instruments of measurement which are usually designed for a specific purpose. A test may contain several items, each item tends to confront the testee with a task to provide means for observing its response to the task. According to Bandele (1992), refers to test as an instrument given to measure a specific type of behavioural change, when given in a standardized and organized systematic condition. The behavior may be knowledge, achievement, intelligence, personality or aptitude. Therefore, test is an instrument, which is mostly used in schools to find out the level of acquired achievement of students in schools in a given instruction. Hence, testers, testees and test cannot dissociate themselves in the school system because there exists a relationship among them Oladunni (1996). Testing involves a systematic sample of an aspect of behaviour from which a wide range of behaviour may be inferred. 
Also, Alonge (1989), testing is a technique of identifying or assessing certain human behaviour of traits which include attitude, performance and interest. The ultimate goals of testing are to provide viable information, which the teachers and students used on their effort to teach and learn. There are traits being measured in the school system, such traits are; achievement, intelligent skills, personality, aptitude or interest. Achievement test consists of easy and objectives test. Objective formant is divided subjectively because every expert arrives at precisely the same score. This test is the most commonly used test formants in primary, secondary and tertiary institutions.

The multiple choice question is generally recognized as the most widely applicable and useful type of objective test item. It is a good measuring instrument for measuring complex outcomes in the knowledge, understanding and application areas. Oladunni (1996), opined that multiple choice type of objective type of test is useful for measuring both the lower order mental processes and the higher order mental processes. This type of test consists of a problem and a list of suggested solutions. The problem is usually stated as a direct question or an incomplete statement which is called "the stem" of the item.

In multiple choice items testees are equally required to "tick' or "shade" the correct response, the list of answers are called alternatives or options. The correct option to an item, is regarded as the key to the item, and the remaining options are called distractors. There are variations of multiple choice formats. They are; one correct answer, example; all these are crops except one: (a) yam, (b) maize, (c) pig, (d) wheat. The correct answer is (c) pig. Then, best answer, example; subsistence agriculture mainly involves; (a) high capital input on the enterprises, (b) food production on large scale farms, (c) food production using family labour, (d) mechanization of all farm operations. The key to the above item is (c).Also, the reversed type; which of the following is not farm implements, (a) cutlass,(b) hoes, (c) cassava, (d) head pan. The key to the above item is (c). While easy formant requires the learner to write a sentence, paragraph which demands as subjective judgment regarding the quality of the written statement. In administrating tests and measuring ability of the students in the school system, the tester must study the test manual before the administration of the test and make sure they follow the instruction; the scoring of the response must be done according to the test manual or specific rules.

There are various scoring techniques like Number right scoring method and Logical choice weight scoring method. In the school, such as primary, secondary and tertiary institutions, number right scoring method is the most commonly used scoring method used by the markers in all the above mentioned institutions including the examination bodies such as Senior Secondary School Examination and National Examination Council. The reason for using this method may be due to the fact that it is the simplest method of scoring multiple choices.

The number right scoring method is the type of scoring method in which a marker assigns one mark to any correct option picked by the students and the number of scores would be placed over the total number of the items. This is only method used by the examiner in most institutions of learning.

Kolawole (2006), mentioned that Number right scoring method is also known as standard conventional method the method occurs where the candidate will obtain either score or (1) one of even (0) zero in a particular item. One mark is awarded for correct or best option which is the (key) and point ( 0 ) is awarded for incorrect option. Then score for any candidate in a test score by number of correct options or number of items he gets right over the total number of items. In this type of scoring, it is very easy for the students to guess the items right. Whereas, the logical choice weight scoring method according to Ajayi (2007), is assumed that the testee either have knowledge or partial or no knowledge to answer a particular item. It is assumed that if the candidate has the knowledge he gets the correct answer, testee are awarded the full point. It is assumed that differential weights will be attached to all the distractors depending on the degree of nearness to the correct option. Kolawole (2011), cited example of scoring through Logical choice weight method as thus: suppose it is a five(5) option item, if testee gets the correct option, testee obtains one(1), second best option 0.75 , third best option 0.50 , fourth best option 0.25 , fifth best option would be 0 .

Secondly, suppose it is a four(4) option item, if testee gets the correct option, testee obtains one(1), second best option testee obtains 0.67 , third best option, testee obtains 0.33 , the fourth best option, testee obtains 0 . Some authors have suggested three (3) to five (5) options to be written for each item. While some believed that a 3-option multiple choice tests is as reliable and discriminating as a 4-option test.

Logical choice weight scoring method tends to be the best method due to the following reasons. Firstly, it will favour the testees because only those who have no idea about a particular item will score zero (0). Secondly, it will force the testers to have full knowledge about the stem, key and alternative option of all the items of the test, above all the degree of nearness response. This method took into cognizance each of the option and the degree of closeness to the key. 
According to Ebel (1965) in an item having four options, if D is the correct option, D will be assigned I mark. If the second option is closer to $\mathrm{D}$, it will be assigned 0.75 and if the third option is closer to $\mathrm{D}$, it will be assigned 0.5 while the last option will be assigned zero (0).Therefore logical choice weight scoring method favour students score. Scores are numerical indicators of student's performance according to a given continuum. Scores provide precision that allows for differentiation between the performances of two candidates who might have scored either excellent or very good or credit.

\section{Statement of the Problem}

Knowledge and capacity to learn usually involved the use of tests. Most institutions make use of number right scoring method to score multiple choice tests due to the fact that the method is easy to score. According to Ebel (1979), the simplest way is to award one mark for each right answer. Using Number right formula: $\mathrm{S}_{\mathrm{I}} \mathrm{R}$, where $\mathrm{R}$ $=$ Right answer, $\mathrm{S}_{\mathrm{i}}=$ score. Reid (1977) noted the obvious disadvantages of the formula used as an upward bias in scores particularly for students with low ability. Take for instance on a test composed of a multiple - choice (MC) items with (n) choice per question, the expected number of right answers attained by random guessing on all items is $\mathrm{Q} / \mathrm{n}$. (i.e question all over number). Which means a testee who has no knowledge at all of the material has an expected score of (2) $S_{1}=Q / n$. This method does not give credit for partial knowledge.

The standard correlation for guessing formula is

$\mathrm{S}=\mathrm{R}-\underline{\mathrm{W}}$

$\mathrm{n}-1$

where

$\mathrm{R}=$ number right

$\mathrm{W}=$ number wrong

$\mathrm{n}=$ number of options. In an attempt to determine the effect of partial knowledge on the reliability of testees scores.

In this study, the following questions were raised.

(i) What is the overall performance of students in the two scoring methods?

(ii) Which of the two scoring methods give the best performance

\subsection{Research hypotheses}

Based on the statement of the problem the following research hypotheses were raised.

$\mathrm{HO}_{1}$ : There is no significant difference between the performance of students scored using number right scoring method and those scored using logical choice weight scoring method.

$\mathrm{HO}_{2}$ : There is no significant relationship between the overall performance of students scored with number right method and students scored with logical choice weight method in schools.

\subsection{Research methods}

A sample of 1200 students was selected. This was made up of students selected from thirty (30) Senior Secondary Schools in three states in south western Nigeria. The instrument for collecting data were four different formats of multiple choice Agricultural science tests. Each of the tests was made up of 60 items with four alternative options to each of the test items was A,B, C, D with different instruments and different methods of scoring. For Number right scoring method $\mathrm{S}_{1}=\mathrm{R}$, one mark assigned to the correct option picked by the testee. Then, for Logical choice weight scoring method, weights are attached to all the distractors depending on the degree of nearness to the correct option. The tests items were drawn from standardized achievement test constructed by West Africa Examination Council, 2000 and 2004 academic years. Validity co-efficient 0.524 was obtained for number right method and 0.624 for logical choice weight method.

Test-retest method was used to ensure the reliability and Co-efficient of stability 0.462 was obtained in number right and 0.610 in logical choice weight method. The test was given and repeated on the same group and the co-efficient of correlation was computed between the first and second sets of scores. Reliability of a test is the extent that repeated measurements give consistent result for individuals.

\section{Discussion}

The study shows that there is a significant difference in the academic performance of students in two scoring methods of multiple choice agricultural science test scores. Academic performance of any group of students is a 
product of many variables including innate abilities of inherited intelligence reinforced or inhibited by environment.

Hawbleton (1970) found that the effect of using scoring method is more or less tests specific. The findings of this study was in line with Alex S (2002) on his own study, he mentioned that scoring multiple choice test are better in differentiating the academic performance of students.

The finding indicated that there is a significant relationship between the performance of students whose scripts were marked with number right scoring method and those marked with logical choice weight scoring method. The finding may be due to the weight assigned to be score in logical choice weight method, this made the finding significant. In addition, logical choice weight method favours the students because only those who have no idea about a particular item will score 0 . It will also force the tester to have full knowledge about the stem, key and the alternative options all the items of the test, above all the degree of nearness to the correct response. The finding in line with Afolabi (1994), the researcher found out logical choice weight is more reliable, the utilization value of the logical choice weight scoring method apart from the basic psychometric attributes which was considered depends to a large extent on the ability of classroom teachers to develop tests item that are suitable for logical choice weight scoring methods.

The logical choice weight scoring method provides wide academic latitude for students to make themselves vulnerable thereby promoting positives effort, risk taking and self belief which are perhaps essential for success in life in general.

Ajibola (2003), carried out a study on multiple choice test among secondary school students in Osun -state, Nigeria. In her findings number right score appears quite inadequate to capture a student cognitive status in a multiple choice agricultural science test scores. Odeyemi (2003), concluded that number right scoring method robs the testee of some points and even gives false assessment of students at some point in time.

\section{Recommendations}

With references to the findings of this study, the following recommendations were made:

1) Logical choice weight scoring method should be introduced to teachers to use as new method of scoring multiple choices in agricultural science and other subjects, the reason is to check mate students random guessing of objectives items.

2) Examination bodies such as West Africa Certificate Examination (WACE), National Examination Council (NECO), Joint Admission and Matriculation Board (JAMB), National Board for Technical Education (NABTEB) and National Teachers' Institute (NTI) and foreign examination bodies should adopt the use of logical choice weight scoring method. Once the candidate is aware of the use of this method, they will make up and be discouraged guessing during the examination.

3) It is also further recommended in all states of the federation and other countries to make the method uniform, in order to make Senior Secondary Certificate Examination (SSCE) results reliable.

4) The method is also recommended for Ministry of Education, examination division to transfer the idea to junior secondary school to make use of the method to score Junior Secondary School (3) objectives test during their final examination.

5) Logical choice weight scoring method could be used in tertiary institutions for post Joint Admission and Matriculation Board (JAMB)

6) Consultancy firms who conducts attitude test for new employees and promotion exercise for their workers should adopt the method.

\section{References}

Afolabi, E. R. I. (1994). Towards an accurate assessment of students cognitive capacity. An evaluation of three scoring procedure in objective testing. OSUA Journal of Education, 1, 42-50.

Ajayi, B. K. (2007). The effect of four scoring methods on multiple choice Agricultural Science Test scores. Former University of Ado-Ekiti now Ekiti State University, Ado- Ekiti. Unpublished Ph.D thesis.

Ajibola, A. A. (2003). Effect of Logical Choice Weight Scoring on the Psychometric Properties of Multiple Choice test among secondary school students in Osun state.

Alex, S. (2002). A new scoring Algorithm for multiple choice test conditional knowledge modern.

Alonge, M. F. (1989). Measurement and Evaluation. Ekiti- state. Adebayo Printing (Nig) Limited. 
Bandele, S. O. (1992). Monograph on Construction of Questionnaire and Rating Scales, University of Ado-Ekiti now Ekiti state University, Ado-Ekiti.

Ebel, R. L. (1979). Essential of Educational Measurement. New Jersey: Prentice Hall.

Hawbleton, R. K. (1970). A comparison of the reliability and validity of two methods for assessing partial knowledge on a multiple choice test. Journal of Educational Measurement, 7, 25-82.

Odeyemi, J. O. (2003). Comparison of the Psychometric Properties of Three-Multiple Choice test. Unpublished M.ed Thesis.

Oladunni, M. O. (1996). Tests, Measurement and Evaluation in Education. Ibadan: Demilade Omotayo.

Ried, F. (1977). An alternative scoring formula for multiple choice and true-false tests. Journal of Educational Research.

Table 1. T-test showing the difference between number right scoring method and logical choice weight scoring method

\begin{tabular}{|l|l|l|l|l|l|l|}
\hline Variables & $\mathrm{N}$ & $\mathrm{X}$ & $\mathrm{SD}$ & $\mathrm{Df}$ & t-cal & t-table \\
\hline Number right scoring method & 300 & 26.85 & 6.006 & 299 & 13.691 & 1.960 \\
\hline Logical choice weight method & 300 & 33.31 & 7.242 & & & \\
\hline
\end{tabular}

Table 1 shows that $\mathrm{t}$-calculated is greater than $\mathrm{t}$-table, thus, the null hypothesis was rejected @ $=0.05$ level of significance. Hence there is a significant difference between the academic performance of students who answered the agricultural objective items through logical choice and Number right methods in favour logical choice weight method.

Table 2. Relationship between the performance of students scored with number right method and students scored with logical choice weight scoring method

\begin{tabular}{|l|l|l|l|}
\hline Variables & N & r-cal & r-table \\
\hline Number right method & 300 & & \\
\cline { 1 - 2 } Logical choice weight method & 300 & 0.248 & 0.195 \\
\hline
\end{tabular}

$\mathrm{P}<0.05$ (significant result)

The result in Table 2 shows that the $r$ cal value for the scores for number right scoring method and logical choice weight was 0.248 which is greater than the $r$ table value (0.195) at 0.05 . The $r \mathrm{cal}>\mathrm{r}$ tab. The hypothesis was rejected. This implies that there is a significant relationship between logical choice weight method and number right scoring method at $\mathrm{a}=0.05$ level of significance. 